\title{
Explanatory roles for minimal content
}

Article

Accepted Version

Borg, E. (2019) Explanatory roles for minimal content. Nous, 53 (3). pp. 513-539. ISSN 1468-0068 doi:

https://doi.org/10.1111/nous.12217 Available at https://centaur.reading.ac.uk/71764/

It is advisable to refer to the publisher's version if you intend to cite from the work. See Guidance on citing.

To link to this article DOI: http://dx.doi.org/10.1111/nous.12217

Publisher: Wiley

All outputs in CentAUR are protected by Intellectual Property Rights law, including copyright law. Copyright and IPR is retained by the creators or other copyright holders. Terms and conditions for use of this material are defined in the End User Agreement.

\section{www.reading.ac.uk/centaur}

\section{CentAUR}

Central Archive at the University of Reading

Reading's research outputs online 


\section{Explanatory roles for minimal content*}

\section{Abstract:}

A standard objection to so-called 'minimal semantics' (Borg 2004, 2012, Cappelen and Lepore 2005) is that minimal contents are explanatorily redundant as they play no role in an adequate account of linguistic communication (those making this objection include Levinson 2000, Carston 2002, Recanati 2004). This paper argues that this standard objection is mistaken. Furthermore, I argue that seeing why the objection is mistaken sheds light both on how we should draw the classic Gricean distinction between saying and implicating, and how we should think about the key philosophical notion of assertion. Specifically, it reveals that these ideas are best understood primarily in sociolinguistic terms (resting on the degree of liability a speaker is held to have for linguistically conveyed content).

According to minimal semantics (Borg 2004, 2012, Cappelen and Lepore 2005) there are propositional, truth-evaluable contents which attach to all well-formed declarative sentences (relativized to a context of utterance), in virtue of the standard lexico-syntactic constituents of those sentences alone. ${ }^{\text {i }}$ Roughly speaking, according to minimalists, what you see is what you get with semantics: (barring ellipsis) the semantic content of a sentence is exhausted by the words and structure its surface shows it to contain. There are two main challenges to any such minimal view:

a. minimal semantic contents are not possible: some/many/all well-formed sentences do not express truth-evaluable contents on the basis of their standard lexico-syntactic elements alone. ${ }^{\text {ii }}$

b. minimal semantic contents are not useful.

One of the main motivations behind objection (b) is the minimalists' stated acknowledgment (e.g. Cappelen and Lepore 1997, Borg 2002) that minimal contents do not and should not capture our intuitive judgements of what is said by a speaker who produces a given sentence. Minimalists hold that a semantic theory is simply not in the business of capturing intuitive judgements of what is said, but why, objection (b) contends, should we allow minimalists to posit minimal contents for sentences which no one who uses those sentences ever expresses (or at least rarely expresses)? Why think that the semantic content of 'Jill got married and had children' is simply Jill got married and had children when someone who utters this sentence standardly says that Jill got married and then had children? Why think that 'Jill took out her key and opened the door' means just what its lexico-syntactic constituents contribute, when everyone who hears this utterance will understand the speaker as having said that Jill took out her key and opened the door with her 
key? As Levinson 2000: 231 objects, the minimalist idea that we can hold semantic content apart from intuitive judgements of expressed content (and explain away any apparent mistake by the semantic theory via appeal to post-semantic pragmatics) seems to rob semantics of its evidential base:

\begin{abstract}
If this tactic is pursued willy-nilly, in violation of our intuitions about truth and falsity, why not claim that any... sentence for which the proponent's semantic theory makes the wrong predictions is in fact patched up by the postsemantic pragmatics and thus is after all correctly analyzed by his unlikely theory.
\end{abstract}

The aim of this paper is to try to provide an answer to this objection to minimalism.i.i My claim will be that minimalists were too quick to agree that minimal contents do not capture our intuitive judgements of what is said and that, when they made this concession, they were operating with too narrow a conception of what is said. Their assumption seems to have been that intuitive judgements of 'what is said' answer to just one criteria and pick out just one content (specifically, concerning indirect speech reports). Instead, I will argue that 'what is said' is a composite notion which answers to a range of different individuating criteria and which thus straddles several different kinds of content. Once we recognise this, and delineate the different conceptions of 'what is said', it becomes clear that, while it is right that minimal content does not capture some intuitive judgements of what is said, there are other quite standard judgements which do in fact require minimal content. Thus, contrary to objection (b), there is a robust explanatory role for minimal content to play. ${ }^{\text {iv }}$ Furthermore, I'll argue that this conclusion matters beyond the confines of the minimalist/contextualist debate. For instance, recognising the composite nature of 'what is said' has repercussions for assertion (and thus for the diverse areas in which the notion of assertion plays a role).

The structure of the paper is as follows: $₫ 1$ briefly introduces two approaches to the semantics/pragmatics divide - minimalism and contextualism - and suggests that, although objection (b) might initially push us towards contextualism, any contextualist account owes an answer to the core question of how to distinguish so-called 'explicatures' (to be described below) from implicatures. My claim will be that, in providing an answer to this question, contextualists can't avoid also providing an answer to objection (b). I will suggest that there are three possible sources contextualists might look to in order to distinguish explicatures from implicatures: (i) formal features of the language, (ii) psychological features of speakers and/or hearers, and (iii) the social role played by different kinds of content. $\$ 2.1$ looks at formal features and $\$ 2 . i i$ examines the psychological option, however I argue that neither (i) nor (ii) are capable of doing the work the contextualist requires and thus they should look to socio-linguistic 
characterisations of what is said ( $\$ 2$. iii). Focusing on the socio-linguistic realm, however, reveals that 'what is said' is a composite notion, capable of picking up on different kinds of contents depending on the aims or purposes of the report, and one version of this socio-linguistic 'what is said' does require minimal content. $\$ 3$ demonstrates this through exploring speech acts that fall within the broader category of saying and implicating, $₫ 4$ looks at some practical applications of this notion of 'what is said', and $₫ 5$ argues that the notion is also needed to capture experimental evidence. Finally, (\$6) considers the repercussions of this composite view of 'what is said' for assertion.

\section{1) Minimalism and Contextualism}

There has been a great deal of debate in philosophy of language recently about how and where to draw the divide between semantics and pragmatics. According to one view minimal semantics - semantic content is exhausted by the standard lexico-syntactic constituents of a sentence. On its own of course this claim doesn't amount to much and would probably be embraced by all parties to the dispute, but minimalists add two further constraints: first, not all (or even almost all) words in the language are contextsensitive (this clause differentiates minimalism from what I would term 'indexicalist' positions, such as Stanley 2002, or Rothschild and Segal 2009, where all or almost all expressions are treated as being, or containing, indexical elements), and, second, the content generated by word meaning and structure alone is, for all well-formed declarative sentences (relativized to a context of utterance in order to allow for reference assignment for indexicals, demonstratives and tense markers), propositional or truth-evaluable content (this clause differentiates minimalism from contextualist positions). That is to say, lexico-syntactic features alone generate more than a mere propositional fragment (contra Bach 1994), or an incomplete logical form (contra Sperber and Wilson 1986). ${ }^{\mathrm{v}}$ As noted above, there are two main challenges to this minimalist approach:

a. minimal semantic contents are not possible (Sperber and Wilson 1986, Carston 2002, Recanati 2004).

b. minimal semantic contents are not useful: they are explanatorily redundant and should thus be rejected (Levinson 2000, Carston 2002, Recanati 2004).

The first objection will not be directly addressed in what follows (see Borg 2004, 2012, Cappelen and Lepore 2005 for extended attempts to respond to this kind of objection), instead I want to focus on (b) since, as some contextualists have noted, it seems in some 
ways a more fundamental challenge. For there is little point in discussing whether or not minimal contents are possible unless there is actually an explanatory need for such contents. As Carston 2008: 366 writes (in her review of Borg 2004):

$[T]$ here is a [more] fundamental question, a preliminary question, concerning the truthconditional desideratum itself. Borg has gone to huge trouble to try to provide us with an intention-free-whilst-still-fully-propositional content for demonstrative (and indexical) utterances. But why is it so darned important that the semantics of a natural language sentence-type (relativized to a formal context) should be a truth-evaluable entity? ...[W] hy should we expect [such contents] from a theory of the meanings encoded by sentence-types, meanings which function as multiply reusable tools in communication and are virtually always supplemented, enriched or otherwise adjusted when so used.

According to (b) then, minimal contents - truth-evaluable contents generated on the basis of standard lexico-syntactic constituents alone prior to rich pragmatic adjustment have no role to play in linguistic understanding. That they lack such a role is clear, advocates of (b) maintain, because minimal contents are not the contents speakers or hearers are consciously aware of during on-line processing of utterances, nor are they the contents by which an utterance is judged intuitively true or false, nor do they capture our intuitive judgements of what is said by a speaker who utters a given sentence. When a speaker says 'There is nothing to eat' the content all parties will consciously entertain is not the minimal There is nothing to eat in some universal domain, rather it will be some more appropriate content such as there is nothing the speaker wants to eat in the kitchen. It is also this refined content which will be used to assess the utterance as intuitively true or false (what the speaker said is not false if there is cabbage soup boiling away next door for instance). Finally, this refined content can also be used as a value of $\mathrm{p}$ in the relevant instance of the schema 'in uttering s, A said that p'. There seems, then, to be no role for minimal content to play. What's more, minimalists themselves seem to agree with these points; for instance, Borg 2012: 49-50 writes:

[M]inimalists are happy to reject the idea that a semantic theory should limn our intuitive judgements of what is said by the utterance of a sentence in a given context. They reject this as an appropriate aim for a semantic theory as they suggest that there is no such thing as a semantically informative notion of what is said by a speaker.

It seems hard to resist the idea, then, that minimal contents are idle wheels in a theory of communication.

In place of minimal contents 'contextualists' argue that we need to recognise three kinds or levels of content involved in linguistic exchanges:

i) Linguistic content (LC): an often/always incomplete LF

ii) Explicature content (EC): what is said/asserted ${ }^{\text {vi }}$

iii) Implicature content (IC): what is (merely) implicated 
Logical forms on this model yield fragments of content or schemata out of which a full proposition can be built (using pragmatic adjustment). ${ }^{\text {vii }}$ Both (ii) and (iii) on the other hand are complete propositions which are the result of this pragmatic adjustment (pragmatic influence that, in both cases, ranges wider than mere disambiguation and reference determination for genuinely indexical elements). However the pragmatic contribution to explicatures is less than that required for implicatures - explicatures are limited pragmatic developments of logical forms and they yield a content which provides the basis for any inference to implicature content. ${ }^{\text {viii }}$ So, for instance, consider utterance B in the following example (from Simons 2017):
A: 'What's that noise?'
B: 'There's a nest in the attic'

\begin{tabular}{|c|l|l|}
\hline \multicolumn{1}{|c|}{ Linguistic Content } & \multicolumn{1}{|c|}{ Explicature Content } & \multicolumn{1}{c|}{ Implicature Content } \\
\hline There is a nest in the attic & $\begin{array}{l}\text { There is an active nest in the } \\
\text { attic } \\
\text { (what is said/asserted) }\end{array}$ & $\begin{array}{l}\text { You should do something } \\
\text { about the wildlife in the attic } \\
\text { (what is merely implicated) }\end{array}$ \\
\hline
\end{tabular}

In order to substantiate this three-way divide however, it is clear that contextualists need to say something more about how explicature content is defined: for any given pragmatic development of a linguistic content, how do we know whether it constitutes part of an explicature or an implicature? Although this question is clearly central, it has proved (as I'll explore below) rather difficult for contextualists to answer.

\section{2) What determines what a speaker says (EC) vs. merely implicates (IC)?}

In drawing the divide between what is said and implicated, there are three broad areas we might look to: (i) the language itself, (ii) the minds of interlocutors and (iii) the social role played by different kinds of contents. (i) and (ii) are explored in detail in Borg 2016, thus I'll survey them only briefly here, suggesting that both face problems. Thus (in \$2.iii) we will turn to look at socio-linguistic features. Focusing on the social aims and purposes of linguistic acts reveals, I will suggest, that we can distinguish different notions of 'what is said' depending on the kind of socio-linguistic role appealed to. However it turns out that it is only those socio-linguistic accounts which appeal to what I'll term 'linguistic liability' which hold out the promise of demarcating explicatures.

\section{2.i) What is said is fixed by the language}


Perhaps when trying to demarcate explicature content, or what is said, we could simply look to the language itself. For instance, perhaps we could define asserted content just via semantic content and declarative mood - for any sentence s uttered by a speaker A in the declarative mood, A asserts the semantic content of s. One problem with this sort of approach is that it seems to run into problems with 'mock assertion', where the speaker produces a sentence in the declarative mood but where the content of that sentence is not, it seems, really asserted (e.g. reductio arguments, certain kinds of loose talk, irony). More seriously, however, this view is problematic since it presumes we already know what the semantic content of a sentence is, yet this is precisely the issue that was supposed to be settled (at least in part) by looking at our intuitions around the notion of what is said. A direct appeal to semantic content and declarative mood is simply empty without a concrete proposal as to what counts as semantic (versus pragmatic) content.

However, there are less simplistic ways in which to appeal to objective, formal features of a language. For instance, advocates of explicatures have argued that which developments or completions of logical form count as what is said can be determined by applying a formal test, such as whether or not the content in question appears within the scope of logical operators such as negation or conditionals (the 'Scope Test', see Carston 1988) or whether it counts as contributing a subpart to the extant logical form of the sentence rather than introducing an entirely new clause (Carston and Hall's 2012 'Locality Constraint'), or whether the content is available to be bound by a quantifier (Stanley's 2002 'Binding Test'); see Borg 2016 for discussion. There are, however, two prima facie problems with any such appeal to formal features: first, it is unclear that they will draw the boundary for what is said exactly where contextualists would like it. For instance, some contextualists have appealed to the Scope Test to show that metaphorical content can count as what is said, but as Camp 2012 has argued, it seems ironic and sarcastic content also embeds under operators (e.g. 'if you have one more brilliant idea like that then you'll be fired'). So, using the Scope Test to fix what is said would yield a category which included content (such as ironic or sarcastic content) traditionally understood as implied rather than said. Second, it seems that any kind of formal test would make the said/implied divide into a sentence-level, context-independent one, for (as some contextualists have noted, e.g. Carston and Hall 2012) formal tests apply at the type level (applying to sentences not merely to utterances of those sentences). So, for instance, we can judge that there is a truth-conditional difference between the following sentences without knowing anything very much about their context of utterance: 
1) If Jill drank five beers and drove home then she can be charged with drinkdriving.

2) If Jill drove home and drank five beers then she can be charged with drinkdriving.

Yet this idea - that explicature content is fixed at the type-level - seems to be in tension with the driving contextualist assumption that explicature content is worked out on-thefly, as it were (with potentially one-off ad hoc concepts being generated to capture specific communicative requirements). ${ }^{\text {ix }}$ Something more flexible than static, sentencelevel tests thus seems to be needed.

\section{2.ii) What is said is fixed by the mind}

Alternatively, we might think to fix what is said by reference to psychological content. Perhaps what is said by A when she utters a sentence $\mathrm{s}$ in a context $\mathrm{c}$ is given by: (a) dispositional psychological content (i.e. content which plays a sub-personal role in utterance interpretation), or (b) conscious speaker content, or (c) conscious hearer content. Such psychological criteria have been appealed to by contextualists, for instance Sperber \& Wilson 1986: 183, Carston 2009: 24 appeal to the notion of 'what the speaker intends to make manifest', while Recanati 2004: 20 famously introduces his 'Availability Test' for what is said, whereby what is said must be content which is intuitively accessible to conversational participants (so long as they count as 'normal interpreters'). However, once again these sorts of criteria look prima facie problematic for grounding the saying/implying distinction. First, the appeal to dispositional, sub-personal psychological content looks too liberal: presumably there will be all sorts of content operative at the sub-personal level which is required in some way for a speaker to arrive at consciously entertained content yet where we have no inclination to count this content as part of what is said (e.g. sub-personal content regarding the language being spoken, the phonetic interpretation of sound-waves, etc.).

Turning to (b) and (c), the problem is that we have no guarantee that the content consciously entertained by interlocutors during on-line processing of communicative acts 
will match the kind of content contextualists have standardly assumed for explicature content. ${ }^{\mathrm{x}}$ This can be seen if we look at cases where communicative acts rely on wellestablished community practices or schemas for linguistic exchanges. Thus consider:

A: Could you come to the rehearsal today?

B: I've got a meeting.

Or:

A: $\quad$ Do you want to have dinner with me?

B: Umm, oh look, there's a three-legged dog over there.

Contextualists suggest that the comprehension process for B's utterances would first involve arriving at some contextually enriched proposition, such as I've got a meeting at the time of the rehearsal or there is an interesting three-legged dog over there. This pragmatically enhanced explicature content then allows the hearer to infer her way to further, implicated propositions: $B$ can't come to the rehearsal / $B$ doesn't want to have dinner with $A$. However, concentrating just on the conscious psychological content entertained by B when producing her utterance or by A when interpreting it, it seems that we have little (theory external) reason to demand that either speaker or hearer must entertain this kind of slightly pragmatically enhanced proposition. What matters to both A and B is getting an answer to A's question and the route to this could just as well go via a general rule (such as 'an apparently irrelevant response to an invitation or request constitutes a rejection of said invitation/request') as via recovery of the explicature. The general suggestion is that, instead of requiring a subject to work their way through all the steps required for the deductive recovery of implicated content, interlocutors might instead 'outsource' parts of this work to external, community-based scripts and heuristics, allowing a hearer to by-pass some of the deductively necessary steps; thus explicature content need not be psychologically real during on-line processing, even if it is part of a rational reconstruction of such on-line processing. ${ }^{x i}$ However, if this is a possibility then 
it can't be legitimate to appeal to the content used in on-line processing to fix explicature content. Appeals to psychological contents, at least as things stand, can't fix what is said versus implied.

\section{2.iii) What is said is fixed by socio-linguistic concerns}

Perhaps instead of treating what is said in formal or psychological terms, we should treat it as a socio-linguistic notion, arising from the relation of language to social norms and cultural expectations. Depending on which kind of socio-linguistic purpose or aspect we are interested in, it seems that we might hold that what is said is fixed by any of the following features (this list is not claimed to be exhaustive):

i. Judgements of reported speech, i.e. A said that $\mathrm{p}$ by her utterance of $\mathrm{s}$ if competent judges would accept a report of the form 'By uttering s, A said that p'. ${ }^{\text {xii }}$

ii. Judgements of the content added to the conversational record, where that record is sensitive to (amongst other things) the mutual knowledge of the participants, the cultural and conversational norms in play, and the social standing of participants.

iii. Judgments of a speaker's liability or culpability for content (strict): a binary notion whereby a speaker A either is or is not held liable for a given content by their utterance of s.

iv. Judgments of a speaker's liability or culpability for content (conversational): a matter of degree where speakers are held more or less liable for a given content via their utterance of $\mathrm{s}$.

All of these seem to be plausible ways to spell out our intuitive, pre-theoretical notion of 'what is said'. Thus, to the extent that we lack a reason to privilege any one of these criteria over the others, 'what is said' turns out to be a composite notion, capable of 
picking out a range of more fine-grained distinctions. However, although they all seem plausible renditions of 'what is said', not all of them are capable of doing the work required here, namely distinguishing between different kinds of contents. For, as is wellknown (see Borg 2004: Ch. 2, Camp 2006, amongst others), (i) and (ii) yield a notion of what is said that includes content standardly taken to be implicature content. So, for instance, take the above example of B's utterance of 'I have a meeting': here it seems that, in the right context, an acceptable report of B's utterance might well be 'B said that she couldn't come to the rehearsal' and this might also be the content B succeeds in placing on the conversational record. ${ }^{\text {xiii }}$ So appealing to either of these first sociolinguistic ways of drawing the divide fails to draw the explicature/implicature divide in the place that contextualists want. ${ }^{\text {xiv }}$ (iii) and (iv), on the other hand, based as they are on the notion of linguistic liability, do hold out the promise of drawing divisions in kinds of content. What we find, however, when thinking about the responsibility a speaker assumes for a given content in virtue of uttering the sentence she does in a given context, and the conditions under which retraction of that utterance is required (on pain of a charge of linguistic incompetence), is that there are different notions of linguistic liability that might be relevant. On the one hand, subjects are sensitive to what I'll term 'strict linguistic liability', a binary notion whereby speakers are or are not held responsible for the strict literal (minimal) content of the sentences they produce. On the other hand, subjects also display a sensitivity to what I'll term 'conversational linguistic liability', according to which speakers are judged to have greater or lesser responsibility for given contents that may be conveyed by their utterances, and where these contents can be ranked in terms of this liability. Clearly, it is this second notion of conversational linguistic liability which is needed to underpin the distinction between explicature and implicature content, but, as we will see in the next section, although conversational linguistic liability does give us a feasible rendition of 'what is said' (and thus that there are 
good grounds, as contextualists have always claimed, for distinguishing explicatures from implicatures on the grounds of judgements of what is said), the notion of strict linguistic liability also has an important role to play. To see this I want to turn in the next section to consider how we individuate classes of speech acts that fall within the category of saying and implicating.

\section{3) The topology of speech acts}

Within the more general categories of asserting or implying it seems that speakers are able to perform distinct kinds of speech act depending on the beliefs and aims of the speaker. So, let us say that a speaker, A, in context c, utters a well-formed sentence s, in the declarative mood, directed at a hearer $\mathrm{H}$. Let us also assume that s has the semantic content $\mathrm{p}$, given by the lexico-syntactic features of $\mathrm{s}$ alone (i.e. minimal semantic content), but that, in c, s may be used to convey some other proposition, or cluster/set of propositions, $\mathrm{p}^{*}$. We can then codify a range of these distinct kinds of speech act on the basis of these features, as in Figure 1.

[Insert Fig. 1 near here.]

\begin{tabular}{|l|l|l|l|}
\cline { 2 - 4 } \multicolumn{1}{c|}{} & \multicolumn{1}{c|}{ Column 1 } & \multicolumn{1}{c|}{ Column 2 } & \multicolumn{1}{c|}{ Column 3 } \\
\cline { 2 - 5 } & $\begin{array}{l}\text { A intends to convey } \\
\mathrm{p}^{\mathrm{xv}}\end{array}$ & $\begin{array}{l}\text { A intends to convey } \\
\mathrm{p}^{*} \text { \& (A believes) } \mathrm{p}^{*} \\
\text { is T }\end{array}$ & $\begin{array}{l}\text { A intends to } \\
\text { convey } \mathrm{p}^{*} \text { \& (A } \\
\text { believes) } \mathrm{p}^{*} \text { is F }\end{array}$ \\
\hline (A believes) $\mathrm{p}$ is T & $\begin{array}{l}\text { (i) Literal } \\
\text { communication }\end{array}$ & $\begin{array}{l}\text { (iii) Non-literal } \\
\text { communication: } \\
\text { precisification cases, } \\
\text { some metaphor. }\end{array}$ & (v) Misleading \\
\hline (A believes) p is F & (ii) Lying & $\begin{array}{l}\text { (iv) Non-literal } \\
\text { communication: } \\
\text { loose talk, similes, } \\
\text { hyperbole, sarcasm, } \\
\text { irony, 'white lies', } \\
\text { reductio. }\end{array}$ & (vi) Deception \\
\hline
\end{tabular}

Figure 1: a partial topology of speech acts subsumed within the categories of asserting and implying. 
In what follows I'd like to explore each of (i)-(vi) in a little more detail and see what they reveal about the kinds of contents which we need to postulate to capture these divergent kinds of speech act.

\section{Column 1:}

i) Literal communication: where the speaker believes the minimal content to be true and this is the content they intend to convey, we have cases of literal communication. This kind of communicative speech act predominantly occurs in contexts where accuracy and precision of meaning matters, e.g. certain kinds of written texts, verbal exchanges in certain settings (e.g. courts of law), or other occasions where content is likely to be assessed in a range of different contexts and where access to important features of the context of utterance may later be limited. The demands for accuracy prompt a speaker to attempt to express the most stable, context-independent content they can (see $\$ 4 . i$ below).

ii) Lying: there are a plethora of different philosophical accounts of lying available but most agree on the idea that lying involves uttering a sentence $s$ where one believes the literal content expressed, p, to be false (or at least doesn't believe it to be true) and yet one intends to convey p. ${ }^{\text {xvi }}$ For instance Saul 2012: 19 offers the following definition: Lying If the speaker is not the victim of linguistic error/malapropism or using metaphor, hyperbole, or irony, then they lie iff (1) they say that P; (2) they believe P to be false; (3) they take themself to be in a warranting context. ${ }^{\text {xvi }}$

As many authors (e.g. Camp 2006, Goldberg 2007, Saul 2012, Michaelson 2016) note, paradigm judgements of lying (which rest on strict linguistic liability) track something very like minimal content. For instance (this example follows Saul 2012: 37) imagine that I'm talking to a rich fundamentalist who is considering leaving her fortune to Jack, so long as he has lived his life fully in line with Christian teaching. Wishing him to get the money but knowing that he had his children out of wedlock, it seems that I can utter: 3) Jack got married and had two children.

I fully expect that my utterance of (3) will lead the rich fundamentalist to believe that Jack got married and then had children, but nevertheless if challenged it seems I can protest that this is not what I said. My utterance is clearly misleading, and intended to be misleading, but intuitively it seems it is not a lie (though cf. Meibauer 2011, Faulkner 2013 for a divergent view). To get these intuitions about lying versus misleading right, 
then, it seems that we need to take the semantic content to be the unenriched minimal content (not the pragmatically enriched, temporally ordered explicature).

Of course, a contextualist might here object that their account is perfectly able to accommodate this intuition, for they hold that explicatures are fixed in context and reflect the conversational needs in play, and that sometimes explicature content may coincide with minimal content (e.g. in cases of literal communication such as those in (i)), while at other times it doesn't. Given this, a contextualist may claim that the case Saul envisages just is one in which the explicature content is the unenriched, minimal content. However this response seems problematic for two reasons: first, even in the context Saul envisages, it seems that it is the enriched reading which will be the first to cross the relevance threshold for the hearer (it is the temporally ordered proposition which matters to them after all), yet still it seems we are happy to allow that all A strictly asserts is the minimal, logical reading. So allowing that the minimal content provides the explicature here would seem to run counter to at least Relevance Theory's claims about how explicature contents are determined. Second, it seems that we can potentially make any situation into one which mirrors Saul's case by asking about the conditions under which a speaker would be held to have lied (rather than misled). Even in a context in which it is the pragmatically enriched, temporally ordered proposition which is communicated to the hearer/added to the conversational record, it seems that we can still ask: 'would A have lied to B if Jack had had children before getting married or would A have mislead B in this situation?'. It is an empirical conjecture (though one borne out by experimental evidence, see $\$ 5$ ) that paradigm judgements about lying track minimal rather than enriched content. ${ }^{\text {xviii }}$

We should note, however, that while Saul allows that minimal content (as given in Borg 2004, 2012) is 'closer to what we seem to need for the lying-misleading distinction' (43) than contextualist accounts of explicature content, it is still not quite, she argues, what is needed. Her objection turns on 'completion' cases where it seems that what is said must involve more than just the very general, existentially quantified kinds of contents proposed by Borg-style minimalism. Her example turns on Clinton's infamous utterance of:

4) There is no improper relation.

Clinton used this utterance in the context of denying the existence of any sexual relation between himself and Monica Lewinski. Intuitively, Saul notes, Clinton's utterance is a classic case of misleading or deceiving: although Clinton's utterance contains only the 
present tense 'is no improper relation' everyone heard him as denying that there was now or ever had been an improper relationship between the two of them. Saul argues that this case shows that, when thinking about lying, minimal content isn't always what is said. For on a minimalist framework, the semantic content of (4) is just what it says on the surface, namely that there are currently no improper relations simpliciter. This proposition is trivially false. Yet, very plausibly, this is not what Clinton said. What he said was that there is no improper relation between himself and Lewinsky. Thus he asserted a (presumably true) pragmatically enriched content - no improper relation between $B C$ and $M L$ at time of utterance - which he used to mislead his audience, who came to believe that there has never been an improper relation between $B C$ and $M L$. $^{\text {xix }}$

However, Clinton's utterance is a complicated case and it is not absolutely clear that Saul's objection goes through. First, we should note that the final point - that what Clinton intuitively said was the enriched proposition - can be conceded by the minimalist, so long as we are thinking of 'what is said' here in terms of (i) acceptable ways in which Clinton's utterance can be reported or (ii) the content he succeeds in adding to the conversational record. As Saul notes, minimalists are happy to agree with contextualists that, understood in this way, what Clinton said may be non-minimal. However, acknowledging this doesn't show that the content in place for judgements of lying and culpability is similarly non-minimal. So, in terms of linguistic liability, should Clinton be viewed as asserting the (presumably) true at time of utterance 'there is no improper relation between myself and Lewinsky' or the trivially false 'there is no improper relation'?

Well, first, to get the more general, trivially false proposition as the minimal semantic content we would need to be sure that there was no genuine ellipsis in this case (something a minimalist might reject). ${ }^{\mathrm{xx}}$ Additionally, however, even if the minimal content of Clinton's utterance were there is no improper relation simpliciter, still this account of the content of his utterance would yield the result that Clinton was not lying. Clinton said something with a trivially false semantic content, but that's okay because (as Fig. 1 shows) we accept people uttering trivial falsehoods on the way to communicating further content all the time (see below on 'non-literal communication' and 'deception'). ${ }^{\mathrm{xxi}}$ If Clinton had been a better man in terms of personal morals, his utterance would have been a perfectly acceptable instance of loose talk: he would have uttered a sentence with a false semantic content (there is no improper relation simpliciter) but thereby conveyed something true (there is not and never has been an improper relation between myself and $M$ s. 
Lewinsky $\left.\left(p^{*}\right)\right)$. As it was, he produced a sentence with a false semantic content and used that sentence to convey something else false. Given that Clinton presumably held this further proposition, $\mathrm{p}^{*}$, to be false, he was engaged in an act of linguistic deception. As we will see below, false statements can often be the grounds for deception and where the falsehood is trivial (as, the minimalist claims, with completion cases) it is plausible to think that our intuitive reactions focus on the deceptive act itself rather than the utterance of the literal falsehood. ${ }^{x x i}$ Unlike Saul, then, I don't think that completion cases suffice to show that something more than minimal content is needed for tracking the lying/misleading distinction. ${ }^{\text {xiii }}$ Clinton's utterance is indeed, as Saul notes, 'a carefully worded denial' and it's carefully worded precisely in order to avoid lying, but one can avoid lying, I want to suggest, while still using a sentence which is literally false.

\section{Column 2}

(iii) and (iv) Non-literal communication: most ordinary communication falls into this column. In typical conversational contexts we are unconcerned with the truth-value attaching to the strict meaning of our sentences, all that is required is that the semantic contents in play successfully serve the purpose of getting our message across and that this message be one that is (held to be) true. For instance, loose talk is, it seems, ubiquitous in our language: when I say 'It's two o'clock' what I almost always mean (and what I'm almost always taken to have said) is that it is roughly two o'clock. This doesn't mean that the sentence literally means roughly or approximately two, or that the sentence content isn't truth-evaluable without the addition of 'roughly' or 'approximately', or that the proposition that it is roughly two is merely implied rather than being asserted. Rather what such cases show is simply that, as contextualists have always argued, we need to allow that sometimes (usually) speakers say or assert (in terms of reported speech, adding to the conversational record, or conversational liability) more than their sentences literally mean. ${ }^{\text {xxiv }}$ The recognition of how much ordinary talk falls into this column should, I think, help to ameliorate the worry (often raised against minimalism) that it generates semantic contents which are either trivially true or trivially false and that such contents have no place in a theory of communication. As we saw above with regard to lying, we can maintain that such contents do have a role to play (i.e. in distinguishing lying from misleading) but that doesn't mean they also always have a role in distinguishing what is asserted from what is implied (because sometimes, when we are assessing what is 
asserted, we are only interested in the content yielded by conversational linguistic liability, see $\left.\int 6\right)$.

\section{Column 3}

(v) Misleading: misleading seems to be a special kind of speech act, where the speaker exploits their knowledge of the literal truth of the sentence they produce paired with the falsehood of the proposition(s) they expect they will communicate via their utterance. Misleading allows a speaker to avoid a charge of lying (and the unmitigated culpability thereby incurred), opening themselves up to a potentially lesser charge (whereby part of the responsibility for $\mathrm{H}$ coming to believe something false lies with $\mathrm{H}$ themselves); e.g. the child's promise 'I will turn the TV off, which an eager parent may well hear as an undertaking to turn the TV off soon. ${ }^{\mathrm{xx}}$

(vi) Deception: Although lying (ii) can be thought of as a special case of deception, it seems that deception cases range more widely than just lying. First, deceptive practices need not involve language at all and, second, deception often involves implied rather than literal meaning. For instance, consider the following case, where A, addressing B, utters (with CAPS denoting stress):

5) SOMEONE hasn't paid you back yet.

Let us suppose (5) is false, in fact all of B's loans have been repaid. However suppose A's purpose in uttering (5) is to convince B that a specific individual, Jones, hasn't repaid her loan. This looks like a pretty classic case of deception on A's behalf though the crucial content is not the literal untruth but the further implied content.

Although the natural language terms 'misleading' and 'deception' almost certainly don't have the strict usages I'm suggesting here, the divisions drawn above do, I believe, codify a range of natural intuitions and judgements on the kinds of conversational speech acts subjects can engage in within the purview of saying and implying. Importantly, from the current perspective, capturing these distinctions turns out to require something very much like the minimal content advocated in Borg 2004, 2012. ${ }^{\text {xxi }}$ Though minimalists were right to maintain that minimal semantic content couldn't and shouldn't be in the business of trying to capture our intuitive notion of what is said where this concerned reported speech or the conversational record, they were wrong to think this showed there was no role for 
minimal content in capturing our intuitions of what is said per se. For, as I've tried to show here, 'what is said' is best understood as a composite socio-linguistic notion, subserving a range of different linguistic purposes, and at least one of these more finegrained notions of 'what is said' - namely that given by strict linguistic liability - is sensitive to minimal content. To drive this apparent need for minimal content home, in the next section I want very briefly to survey some of the practical uses to which strict linguistic liability (and therefore minimal content) is put, before turning (in \$5) to consider some experimental work in this area.

\section{4) Practical applications of strict linguistic liability}

i) In legal interpretation, many jurisdictions employ rules which rely on strict linguistic liability. For instance, two of the three rules of statutory interpretation standardly applied in the UK - the 'Plain Meaning Rule' and the 'Golden Rule' - rest on minimal semantic content. Thus the Plain Meaning Rule requires the interpretation assigned to legal statements to coincide with the literal meaning of the sentences used to express those judgements, while the Golden Rule allows departure from literal meaning, where the results of literal interpretation lead to absurd results. As O'Sullivan 2015 has argued, historically, English courts adopted a literal (or 'textualist') approach to contractual construction, focussing almost entirely on the words of a document in order to work out its meaning and ignoring the context or background. According to this approach, subject to very limited exceptions:

$\ldots$ it is the duty of the court, which is presumed to understand the English language, to construe the document according to the ordinary grammatical meaning of the words used therein, and without reference to anything which has previously passed between the parties to it. ${ }^{x x v i i}$

O'Sullivan suggests that, although there was a shift away from such literalism (at least in UK contract law) in the 1970's, there is evidence of move back towards weighting of standing meaning over contextual meaning in recent judgements. ${ }^{\text {xxiii }}$ Note, however, that the argument here is not that literalism is right, but rather that it is not even possible to understand literalist moves without recognising a practical interpretative role for minimal content). ${ }^{\text {xix }}$

This point holds for criminal as well as contract law, and with respect to very general, putatively incomplete minimal contents. For instance consider the case, discussed at length in Neale 2007, of US statute 18 U.S.C. \924(c)(1), which mandates a five-year consecutive sentence for anyone who "uses or carries a firearm during and in relation to any crime of violence or drug trafficking". In Smith v. United States (1993), a 
defendant appealed the application of this penalty in his own case as he had attempted to trade a firearm for drugs rather than using the gun in a more conventional sense.

However the defendant eventually lost his appeal, with the Supreme Court finding that his actions did constitute the use of a firearm in relation to a crime of drug trafficking. The opinion of the Supreme Court stated that:

In affirming Smith's conviction and sentence, the Court of Appeals held that $\int 924(\mathrm{c})(1)$ 's plain language imposes no requirement that a firearm be "used" as a weapon, but applies to any use of a gun that facilitates in any manner the commission of a drug offense...Had Congress intended $\int$ 924(c)(1) to require proof that the defendant not only used his firearm but used it in a specific manner -- as a weapon -- it could have so indicated in the statute. However, Congress did not. The fact that the most familiar example of "using ... a firearm" is "use" as a weapon does not mean that the phrase excludes all other ways in which a firearm might be used.

Their judgement continued:

We are not persuaded that our construction of the phrase 'uses ... a firearm' will produce anomalous applications ... \ 924(c)(1) requires not only that the defendant 'use' the firearm but also that he use it 'during and in relation to' the drug trafficking crime. As result, the defendant who 'uses' a firearm to scratch his head ... or for some other innocuous purpose, would avoid punishment for that offense altogether: Although scratching one's head with a gun might constitute 'use', that action cannot support punishment under $\int 924$ (c) (1) unless it facilitates or furthers the crime; that the firearm served to relieve an itch is not enough. . . Under the dissent's approach ... even the criminal who pistol-whips his victim has not used a firearm within the meaning of $\$ 924(\mathrm{c})(1)$, for firearms are intended to be fired or brandished, not used as bludgeons.

Again, the claim here is not that this judgement was the right or the only one to reach in this case (though, contra Neale 2007, it seems reasonable to me) but simply that we cannot even make sense of the Supreme Court judgement unless we admit a propositional content for the statute independent of rich pragmatic adjustment. ${ }^{\mathrm{xx}}$ And further examples aren't hard to find; see for instance $R v$ Harris (1836), 7 C\&P 446, where a defendant who had bitten off someone's nose and was convicted under a statute making it an offence 'to stab cut or wound' had his conviction quashed on appeal where the court found that the literal understanding of 'stabbing, cutting or wounding' required the an instrument to be used. Or Fisher v Bell (1961), 1 QB 394, where a defendant's conviction for 'offering a flick knife for sale' was overturned when the court ruled that displaying a flick knife in shop window, with a price tag attached, did not constitute an 'offer' in the technical sense but was rather 'an invitation to treat'. In all such cases, making sense of what the courts were doing (whether we agree with the judgements or not) requires appeal to minimal content.

ii) The criminal charge of perjury also seems to rely on strict linguistic liability. Perjury is often defined as the crime of intentionally lying after being duly sworn to tell the truth by a notary public, court clerk or other official. Perjury, like lying, then requires minimal 
content - one shouldn't, it seems, be open to a charge of perjury through explicature content (a point borne out by all the examples of perjury I've examined; see also Saul 2012: 95). .xxi $^{x}$

iii) Defamation: most legal definitions recognise two forms of defamation:

a) Defamation per se: where the words themselves are actionable; aligns with (4.ii) \& (4.iv).

b) 'innuendo' - classes of words that are not actionable in and of themselves but are made actionable through the presence of certain extrinsic factors, where the utterance is intended and taken to be malicious.

Defamation per se apparently tracks judgements of strict linguistic liability and therefore minimal content. A speaker can be charged with defamation per se, either via libel or slander, if the minimal meaning of the sentence they produce is false and it causes damage to the reputation of the individual named in the defamatory act. However, courts also recognise that it is possible to defame others through pragmatically conveyed content, so that although the linguistic meaning of the sentences produced is unobjectionable the speaker who utters them thereby conveys malicious content.

iv) In games a distinction is often drawn between 'the rules of the game' and 'the spirit of the game', again revealing judgments of strict linguistic liability versus conversational linguistic liability. So, for instance, the Laws of cricket, as set by the Marylebone Cricket Club, state (Law 42.15) that 'The bowler is permitted, before entering his delivery stride, to attempt to run out the non-striker'. That is to say, if, once the bowler has begun his run-up but before he releases the ball, he sees that the batsman at the non-strikers end has moved out of an area demarcated as the batsman's 'ground', the bowler is entitled, within the rules of the game, to dislodge the bails at the non-strikers end and have the batsman given out. However, while a bowler who does so is judged to be playing within the rules of the game, such a move is thought to be unsporting (unless it is preceded by a warning to the batsman). Thus a player who does attempt to run out the non-striker in this way is held not to be 'playing within the spirit of the game' and is open to chastisement along these lines. This robust, conventional distinction again shows our willingness to hold apart strict, linguistic liability and conversational linguistic liability, revealing a practical dimension to our sensitivity to both minimal and explicature content. $^{\text {xxxii }}$ 


\section{5) Experimental evidence}

In the previous sections I argued that, contrary to a core concession by minimalists, subjects do have intuitions about 'what is said' that track minimal content (as revealed by their practices surrounding strict linguistic liability). It is easy to overlook this fact if one misses the point that 'what is said' is a composite notion - though we sometimes think of what is said as given by correct indirect speech reports or by summaries of the content the speaker succeeds in placing on the conversational record, we also sometimes treat 'what is said' in terms of linguistic liability and when thought about in these terms we find a clear role for minimal content to play. Thus the complaint that a minimalist approach is ungrounded as it is divorced from our intuitive judgements about expressed content, can be rejected. Furthermore, this contention - that subjects are in fact sensitive to minimal semantic content when making (at least some) intuitive judgements of what is said - is (I'll argue in this section) backed up by experimental evidence.

A first, well-established, point to note is that children tend to be 'more logical' than adults. For instance, in examples where adults are likely to give pragmatically narrowed readings to logical terms, children will often favour more liberal, literal readings. Thus studies have shown that children are less likely to draw scalar implicatures than adults (e.g. hearing 'some Fs are G' as meaning some and possibly all Fs are G, rather than the enriched reading some and not all Fs are G; see Rips 1975, Noveck 2001, Papafragou and Musolino 2003), while Noveck et al 2009 have demonstrated that even with a classic explicature content, such as the move from 'and' to 'and then', children are much more likely than adults to go with the unenriched, bare (conjunctive) meaning. In addition, recent work by Crain has shown that children are more likely to give literal readings to logical terms even if the language they are acquiring is one in which pragmatically enhanced readings turn out to be something like default interpretations (e.g. Tieu, Romoli, Zhou \& Crain 2015). Furthermore, we should note that since the experimental protocols used in these experiments involve asking subjects to make judgements of truth or falsity it seems that the content subjects are judging has to be truth-evaluable, not merely some fragment of content; see Crain \& Thornton 1998 for discussion of truth value judgement tasks. Thus experimental work supports the minimalist claim that what subjects are capable of recovering prior to rich pragmatic enhancement is genuinely propositional, truth-evaluable content. 
Related to this finding, Paltiel-Gedalyovich 2011 shows that adult and child performance differs in terms of the degree of uniformity of judgements. So, for instance, she found universal agreement amongst adult Hebrew subjects when asked to make a truth-value assessment of a situation that coincided with the literal meaning of a sentence containing a logical expression (e.g. judging the Hebrew version of the sentence 'Ernie ate an apple and a banana' true when Ernie has been seen eating an apple and eating a banana). She also found that adults showed a uniform response when judging scalar implicatures (e.g. uniformly rejecting the sentence 'Big bird is wearing a scarf or a hat' when Big bird is pictured wearing both). However, turning to children, the findings differed: though by 5 years old children provided uniform, adult-like responses with respect to judgements involving literal meaning, there was no uniformity in scalar responses (either within a single subject across different scalar examples or as a group across a single scalar example). Thus even the oldest children in the study ( 9 years) were almost as likely to respond with unenriched readings to scalar examples as with enriched readings (e.g. accepting 'Big bird is wearing a scarf or hat' in the above example). What findings in this area show, then (as Pouscolous et al 2009 stress), is not that children are unable to recover either scalar implicatures or other kinds of pragmatically enriched meanings - on the contrary, given enough experimental or contextual scaffolding, children do recover adult-like interpretations in these cases - but it seems clear that these interpretations do not come as naturally to young children as they do to adults. Hearing pragmatically enriched readings signifies a developmental achievement for children. Thus if we want to model early linguistic understanding correctly, it seems that we need to posit minimal meanings. ${ }^{\text {xxxiii xxxiv }}$

Finally, recent experimental work by Sternau et al 2015 assessing judgements of, on the one hand, speaker's commitment and, on the other, deniability indicates that subjects do consistently distinguish what they call 'bare linguistic meaning' (minimal content), explicatures, and different strengths of implicatures. ${ }^{\mathrm{xxv}}$ Thus Sternau et al 2015: 98 conclude:

The linguistic level...emerges as a distinct level of interpretation, distinguishable not only from both types of implicatures, but also from the explicature, thus manifesting its own discursive pattern. This finding, attesting that linguistic meanings may have a distinct psychological role interactionally as well as theoretically, supports the Minimalists' assumptions about the important role of the unenriched linguistic level. It argues against the Maximalists' claim (Recanati 2004 and onwards; Carston, 2012, p.c.) that this level is not consciously accessible to interlocutors.

It seems then that experimental work backs up the contention that far from being an idle explanatory wheel, minimal content is needed to explain and predict our 
linguistic judgments, both from developmental and cross-sectional perspectives. When we talk about 'what is said' by a speaker there are a range of things we might mean and a range of different socio-linguistic aims we might be trying to meet. Contextualists are right to note (and minimalists are right to agree) that a key notion of 'what is said' tracks judgements of reported speech or the content added to the conversational record and that such judgements do not track minimal content. However, since neither intuitive judgements of reported speech nor of the content added to the conversational record track explicature (as against implicature) content either, this point can provide little succour to the contextualist. Instead, then, if she is interested in individuating her favoured notion of explicature content the contextualist is best advised to look to the idea of linguistic liability: we can and should recognise a scale of contents, ranked in terms of judgements of conversational linguistic liability, and it is this ranking which grounds the EC/IC divide. Yet once we focus on the role of conversational linguistic liability what we find is that there is another notion - strict linguistic liability - capable of yielding an alternative notion of 'what is said', one which is sensitive to minimal content. This notion has a key role to play in holding apart lying, misleading and deceiving, and in characterising literal communication versus loose talk, and these distinctions also embed in a number of practical applications, e.g. in the law. Furthermore, as we have seen in this section, minimal content is needed to explain the linguistic profile of children as opposed to adults and to underpin the range of judgements adult subjects make in tests of commitment and deniability. I suggest then that the standard objection to minimalism with which this paper began can be rejected: contrary to a common contextualist view, minimal contents do have a robust explanatory role to play. Though the contextualist is right that there is a role for explicatures to play as well, this can only be alongside minimal content not instead of it. Finally, I want to close by considering how the view that 'what is said' is a composite notion fits with the epistemic work of assertion.

\section{6) Is 'what is said' the same as 'what is asserted'?}

As noted at the outset, 'what is said' is often taken to be synonymous with 'what is asserted' and one reason for wanting to get clear on the former notion might stem from the belief that it will help us to get clear on the latter. Furthermore, it seems that accounts of assertion often take a grip on the content expressed by an utterance for granted; for instance, in the recent debate surrounding norms of assertion, the focus has been on the right kind of normative constraint (i.e. must one know that $\mathrm{p}$, have a 
justified belief that $\mathrm{p}$, etc.) but there has been little discussion of what makes some proposition $\mathrm{p}$, rather than $\mathrm{p}^{*}$, the asserted content of that utterance. However, the question facing us now is: if, as argued in this paper, 'what is said' is a composite notion, spanning different contents depending on the precise socio-linguistic aim in play, what does this mean for assertion?

If 'what is said' is a composite notion and we want to equate 'what is asserted' with it, we have two options: either what is asserted is an equivalently composite notion, capable of spanning all the kinds of contents that 'what is said' can embrace, or 'what is asserted' equates to 'what is said' only under some versions of the latter notion. This first suggestion seems mistaken, given the point stressed above that some renditions of 'what is said' (indirect speech reports and conversational record) allow implicature content to count as 'what is said'. Yet, we don't want implicatures to be asserted: first, it seems pretty much definitional of implicatures that they are indirectly conveyed, rather than being asserted, and, second, implicatures don't seem to come with the appropriate kinds of epistemic guarantees. For assertion to serve as a basis for knowledge acquisition (through testimony), we need asserted content to meet a certain standard of epistemic probity (speakers should know, justifiably believe, etc., asserted content), but given that the interpretative burden involved in arriving at an implicature is carried at least in part by the hearer, it seems we cannot simply assume that speakers meet such epistemic standards with regard to this kind of content. So 'what is asserted' can't, it seems, equate with reported speech or conversational record versions of 'what is said'.

So should we take 'what is asserted' to go with minimal content (i.e. tracking judgements of strict linguistic liability), or explicature content (demarcated by judgements of conversational linguistic liability), or both? I would suggest that the last position is the most appealing, for while literal communicative contexts, judgements of lies, etc., show that we sometimes take speakers to have asserted minimal contents, on other occasions we are clearly willing to allow that speakers assert explicature content. For instance, consider the following, well-known cases:

Whistle Blower: A asks B why Jones is taking her ex-employer to court and B replies 'Jones blew the whistle on poor practices at work and was sacked'. A is held much more conversationally liable for a somewhat pragmatically enriched content, such as Jones blew the whistle on poor practices at work and as a result was sacked, than for a pervasively pragmatically influenced content, such as Jones has a strong case against her ex-employer. 
Handwriting Reference: A writes only 'Jones has nice handwriting' in a reference for a philosophy job. A is held more responsible for a somewhat pragmatically enhanced content $\mathrm{p}^{*}$ (e.g. Jones has nice handwriting for a philosophy graduate) than for a more removed content such as $\mathrm{p}^{* *}$ (Jones has little philosophical talent).

In these cases, depending on the wider conversational settings, we may accept the speaker asserted the slightly pragmatically enhanced content, while they merely implicate the more thoroughly pragmatically delivered content. ${ }^{\text {xxvi }}$ To accommodate our intuitive judgements here then, it seems we must also view 'what is asserted' as a composite sociolinguistic notion: whether a speaker asserts minimal content or explicature content (or both) will depend on the kind of linguistic exchange taking place. .xxvii $^{\text {. }}$

Furthermore, because there is no requirement that either liability-based notion of assertion deliver content which matches something in the interlocutors psychological make-up (either at the conscious or the sub-personal level) we can accommodate the idea that sometimes contents properly classified as implicatures are accessed directly - just as there are 'direct access metaphors', so there are 'direct access implicatures'. In this way, asserted content isn't simply 'heard first' content, rather what is asserted will be determined by the judgements of linguistic liability made by competent subjects, where these are sensitive to whether strict or conversational liability is in order. Assertion is more restrictive than saying - to assert p, p must be either the minimal or the explicature content of one's utterance, whereas, in the right context, one can count as saying p even if $\mathrm{p}$ is merely an implicature (e.g. if we are interested in reported speech or the conversational record) - but both notions should be thought of in socio-linguistic terms, relating to the role certain contents play in judgements of speaker responsibility, rather than reflecting something embedded in the language or in the on-line processing of language users.

\section{7) Conclusion}

This paper opened with a standard objection to minimal semantics, namely that minimal contents are explanatorily redundant. The main aim of the paper has been to show that this objection is ungrounded: there is a robust explanatory role for truthevaluable minimal content to play. To see this, we need to recognise that 'what is said' is a notion which has its home in the socio-linguistic realm, depending on the roles played by different kinds of content. Looking to this realm, what we find is a core notion of 
linguistic liability, i.e. the extent to which a speaker is held responsible for a linguistically conveyed content. Linguistic liability, I have suggested, comes in two varieties: strict and conversational. Conversational linguistic liability ranks potential interpretations in terms of the degree to which a speaker's utterance makes her responsible for a given content, and these ranked interpretations play a crucial role in distinguishing explicatures from implicatures. They also help to fix (in part) what a speaker is able to assert, versus only indirectly convey, by her utterance. Strict linguistic liability, on the other hand, is crucial in individuating different kinds of speech acts, such as lies, loose talk, similes, hyperbole, irony and metaphor. It also helps to fix what a speaker can assert by her utterance.

Without the kind of content predicted by minimalism, we would be unable to explain the distinctions ordinary speakers draw, nor the practices they engage in with their language, nor the developmental trajectory of language acquisition. For all these reasons, then, the standard objection - that minimal contents are explanatorily otiose - should be rejected.

\section{Bibliography}

Bach, K. 1994. Semantic slack: what is said and more. In Foundations of Speech Act Theory: philosophical and linguistic perspectives, S. Tsohatzidis (ed). London: Routledge. 267-291. Bach, K. 2006. The top ten misconceptions about implicature. In Drawing the Boundaries of Meaning: Neo-Gricean studies in pragmatics and semantics in honor of Laurence R. Horn, B. Birner and G. Ward (eds). Amsterdam: John Benjamins. 21-30.

Borg, E. 2002. The semantic relevance of 'what is said'. Protosociology 17: Semantic theory and reported speech, 6-24

Borg, E. 2004. Minimal Semantics. Oxford: Oxford University Press.

Borg, E. 2007. Minimalism versus contextualism in semantics. In Context Sensitivity and Semantic Minimalism: Essays on Semantics and Pragmatics, G. Preyer and G. Peter (eds). Oxford: OUP. 546-571. Reprinted in The Semantics-Pragmatics Boundary in Philosophy, 2013. M. Ezcurdia and R. Stainton (eds). New York: Broadview Press.

Borg, E. 2012. Pursuing Meaning. Oxford: Oxford University Press.

Borg, E. 2016. Exploding explicatures. Mind and Language 31: 335-355.

Camp, E. 2006. Contextualism, metaphor, and what is said. Mind \& Language 21: 280309.

Camp, E. 2012. Sarcasm, pretense, and the semantics/pragmatics distinction. Nous 46: 587-634. 
Cappelen, H. \& E. Lepore. 2005: Insensitive Semantics: a defense of semantic minimalism and speech act pluralism. Oxford: Blackwell.

Caret, R. 1985. Comparative normative hermeneutics: scripture, literature, constitution. Southern California Law Review 58: 37-134.

Carson, T. 2006. The definition of lying. Nous 40: 284-306.

Carston, R. 1988: Implicature, explicature, and truth-theoretic semantics. In Mental

Representations, R. Kempson (ed). Cambridge: Cambridge University Press, 155-81.

Carston, R. 2002. Thoughts and Utterances. Oxford: Blackwell.

Carston, R. 2008. Review of Minimal Semantics. Mind \& Language 23: 359-367.

Carston, R. 2009: Relevance theory: contextualism or pragmaticism? UCL Working Papers in Linguistics 21.

Crain, S. \& Thornton, R. 1998. Investigations in Universal Grammar. MIT Press.

Fodor, J. 1983. Modularity of Mind. Cambridge, MA: MIT Press.

Geurts, B. \& Rubio-Fernández, P. 2015. Pragmatics and processing. In Investigating

Meaning, N. Hansen and E. Borg (eds). Special volume, Ratio 28: 446-469.

Goldberg, S. 2015. Assertion. Oxford: Oxford University Press.

Hansen, M. 2008. On the availability of 'literal' meaning: evidence from courtroom interaction. Journal of Pragmatics 40: 1392-1410.

Kölbel, M. 2011. Conversational score, assertion and testimony. In Assertion: New Philosophical Essays, J. Brown and H. Cappelen (eds). Oxford: Oxford University Press. Leidkte, F. 2011. The impact of literal meaning on what-is-said. In Experimental Pragmatics/Semantics, J. Meibauer \& M. Steinbach (eds). Amsterdam: John Benjamins. 4362.

Meibauer, J. 2014. Lying at the Semantics-Pragmatics Interface. De Gruyter Mouton.

Michaelson, E. 2016. The lying test. In Mind \& Language 31: 470-499.

Neale, S. 2007. On location. In O'Rourke, M. \& C. Washington (eds), Situating Semantics. Cambridge, MA: MIT Press. 251-393.

Noveck, I. 2001. When children are more logical than adults: experimental investigations of scalar implicatures. Cognition 78:165-188.

Noveck, I. 2004. Pragmatic inferences related to logical terms. In Experimental Pragmatics, I. Noveck \& D. Sperber (eds). Basingstoke: Palgrave Macmillan. 301-321.

Paltiel-Gedalyovich, L. 2011. Adult response uniformly distinguishes semantics from pragmatics. In Experimental Pragmatics/Semantics, ed. J. Meibauer \& M. Steinbach.

Amsterdam: John Benjamins. 101-127 
Papafragou A., \& Musolino, J., 2003. Scalar implicatures: experiments at the semanticspragmatics interface. Cognition 86:253-282.

Pouscoulous, N., \& Noveck, I. 2009. Going beyond semantics: The development of pragmatic enrichment. In Language Acquisition. S. Foster-Cohen (ed) Palgrave. 196-215 Pupa, F. 2015. Impossible interpretations, impossible demands. Linguistics and Philosophy 38: 269-287.

O’Sullivan, J. 2015. Update on contract law. Freshfields Brukhaus Derringer training presentation, September 2015.

Rips, L.J. 1975. Quantification and semantic memory, Cognitive Psychology 7: 307-40.

Rothschild, D. and G. Segal. 2009. Indexical predicates. Mind and Language 24: 467-493.

Saul, J. 2013. Lying, Misleading, and the Role of What is Said. Oxford: Oxford University Press.

Simons, M. 2017. Local pragmatics in a Gricean framework. Inquiry 60: 466-492.

Sorenson, R. 2007. Bald-faced lies! Lying without the intent to deceive. Pacific Philosophical Quarterly 88: 251-264.

Sorenson, R. 2017. Lucifer's logic lesson: how to lie with arguments. Proceedings of the Aristotelian Society Supplementary Vol. XCI: 105-126.

Sperber, D. and D. Wilson. 1986. Relevance: communication and cognition. Oxford: Blackwell.

Stanley, J. 2002. Making it articulated. Mind \& Language 17: 149-68.

Sternau, M., Ariel, M., Giora, R. \& O. Fein. 2015. Levels of interpretation: new tools for characterizing intended meanings. Journal of Pragmatics 84: 86-101.

Stokke, A. 2013. Lying and asserting. Journal of Pbilosophy CX: 33-60.

Stokke, A. 2017. Conventional implicature, presupposition and lying. Proceedings of the Aristotelian Society Supplementary Vol. XCI: 127-147.

Tieu, L., Romoli, J., Zhou, P., Crain, S. 2015. Children's knowledge of free choice inferences and scalar implicatures. Journal of Semantics 32: 1-30.

Winer, G., Cottrell, J., Mott, T., Cohen, M., \& Fournier, J. 2001. Are children more accurate than adults? Spontaneous use of metaphor by children and adults. Journal of Psycholinguistic Research 30: 485-96.

\footnotetext{
${ }^{*}$ For helpful comments and corrections thanks are due to audiences at the $2^{\text {nd }}$ Pervasive Context conference, Beijing 2015, the Zurich Early Career Conference 2016, the St. Andrews workshop on Testimony and Context 2016, and an Edinburgh research seminar 2016, as well as to two anonymous referees for this journal. Research for the paper was supported by an AHRC Research Network award on
} 
'Pervasive context-sensitivity in natural language', 2014-2016, held between University of Reading and Peking University.

i This definition is vague in certain ways, e.g. what counts as a 'standard lexico-syntactic constituent'? Depending on how this point is precisified, minimalism might or might not include a position like Jason Stanley's (see, e.g. Stanley 2002) where the lexico-syntactic elements of sentences are held to be largely (or perhaps entirely) context-sensitive. I'll offer a fuller definition of minimalism below (section 2) which rules out a Stanley-type view, however for a fuller discussion of some of the different ways in which minimalism might be defined see Borg 2007.

ii We might characterise (a) and (b) as incompleteness (or underdetermination) objections vs. inappropriateness objections to minimalism. Incompleteness objections (a) won't be addressed directly in what follows as full discussion of the various attempts to answer this challenge would take us too far from the main concerns of the paper (see Borg 2004, 2012, Cappelen and Lepore 2005 for extended attempts to answer objection (a)). However, in what follows I adopt a strong version of minimalism whereby complete propositions are held to be expressed even by putatively incomplete sentences. So, for instance, I adopt the treatment of 'ready' proposed in Borg 2004, 2012, which assumes that the lexicon marks two argument places for this expression, so that the proposition literally expressed by a sentence like 'Pat is ready' is Pat is ready for something (see Borg 2012: 92-102, 202-213; note this treatment might not be right for all putative incompleteness cases, see Borg 2012 for this claim). I'll try to provide some support for this strong version of the view in what follows by suggesting cases where minimal content of this kind has a role to play (though see also n.iv) but for a fuller defence of this strong version of minimalism see Borg 2004, 2012. Thanks to a Reviewer for this journal for stressing the need to clarify this point.

iii There are extant suggestions as to how to answer this challenge, for instance via appeals to the needs of modularity and impairment cases (Borg 2004). However this paper aims for an extended defence and from a different angle.

iv A word on the scope of the challenge to minimalism here, for both Reviewers for this journal raised (in different guises) the worry that while the paper might succeed in showing a partial role for minimal content (whereby either some kinds of minimal content have an explanatory role to play or on some occasions minimal content has a role to play) it didn't clearly establish a more universal role, whereby all types of minimal content have a role to play on all occasions. While I think this concern is certainly well-taken there are two points I'd make in response: first, I take it that to answer the extant challenge to minimalism (see, e.g. Carston 2008: 366, quoted in \$1) it needs to be shown that in general there is explanatory work for minimal (truth-evaluable, sentence-level) type contents to do. This paper then aims to establish that at a minimum a wide range of standard linguistic judgements that ordinary speakers make in fact require sensitivity to truth-evaluable minimal content and thus that the extant charge of explanatory redundancy levelled at minimalism is ill-founded. Second, however, I do think there are responses to be made to each of the specific challenges raised by the Reviewers. See n.xxix for the worry that only some kinds of minimal content have a role to play; see n.xviii for the worry that minimal content only has a role to play on some occasions. $\checkmark$ See Borg 2012: 4-5 for a 4-clause definition of minimalism along these lines.

vi The term 'explicature' comes from Sperber and Wilson 1986. Other terms here include Bach's 1994 'impliciture' and Recanati's 2004 'what is said'.

vii This constitutes a core point of difference with minimalism, which claims that the content at (i), before rich pragmatic adjustment, is already something truth-evaluable/propositional.

viii Though notice that in Relevance Theory explicature content may also be refined in light of implicatures, through a process of 'mutual adjustment'; see Carston 2002.

ix This is something that both Sperber and Wilson, and Carston explicitly recognise. For instance, Carston 2002: 191 suggests that it is really the communicative principle of relevance itself that will sort explicatures from implicatures.

x Focussing on quantifier-restriction, Pupa 2015 also objects to this kind of psychological rendition of free enrichment (his argument turns on a failure to account for impossible enrichments). As he writes "In the normal course of events, actual speakers don't intend a particular restriction. When pressed, actual speakers are unwilling or unable to specify a particular restriction. When asked, actual speakers are unlikely to assent to the completions that theorists select on their behalf. The [above] proposals simply paper over a rather messy situation with more tractable circumstances" (285).

xi This point obviously parallels the response made on behalf of Grice's account of the derivation of implicatures, when it was charged with being too cognitively demanding; see, e.g., Bach 2006; see also Geurts et al 2015.

xii It is this socio-linguistic rendition of 'what is said' that I suggest minimalists really had in mind when they claimed that minimal content was not and should not be in the business of capturing intuitions about what is said (see, e.g., Borg 2004 Ch.2, \$2.5, Borg 2012, Ch. 2). What these discussions overlook, I claim, is that judgements of reported speech provide just one version of 'what is said' and that there are other, non- 
equivalent but perfectly acceptable versions (such as in (iii) above) which yield a much more central role for minimal content.

xiii Thus I want to reject what I think is a fairly common view: that implicature content is 'off the conversational record' (e.g. see Kölbel 2011: 70). Assuming that the record keeps track of content interlocutors take to be operative in the context and that it captures the content which, in part, determines a speaker's next conversational move, it seems unquestionable that implicature content must figure on it. If not, it seems interlocutors would need simultaneously to keep track of two distinct bodies of information: the official, implicature-free record and the full body of linguistically conveyed content capable of influencing their conversational moves. This seems an unnecessary cognitive burden on subjects, especially given evidence showing that subjects in fact have much better recall for the general gist of a communicative act over its precise formulation; see Fodor 1983: 56-60.

xiv Of course, a contextualist might at this juncture bite the bullet and simply agree that sometimes the explicit content of an utterance of 'I have meeting' is I can't have lunch with you, or that (in Grice's reference case) the sentence 'Jones has nice handwriting' explicitly conveys Jones has little philosophical talent. Doing so, however, would run counter to the clear intuitions Grice tapped into and which underpin the entire category of implicatures.

xv The rather vague term 'A intends to convey $\mathrm{p}$ ' is used in order to avoid a debate about exactly what the speaker intends here: do they intend a hearer $\mathrm{H}$ to believe $\mathrm{p}$ or do they intend to have $\mathrm{p}$ added to the conversational record? One place where this becomes pressing concerns lying. So Carson 2006 and Sorensen 2007 reject so-called 'deceptive' definitions of lying (i.e. those which include a clause requiring the speaker to intend the hearer to believe something the speaker believes to be false), as it seems that lies can intuitively occur even in contexts where a speaker cannot intend an audience to believe that p. For instance, lies can occur in contexts where the speaker knows that her audience will not believe her (e.g. because it is obvious to everyone that what she says is false, such as the child who says 'I didn't break it' when everyone is looking at the smashed cup that has just fallen from their hands). For this reason, then, accounts which see the speaker as intending to add to the conversational record may seem preferable (see Stokke 2013 for discussion). However, to avoid full discussion of these issues, I opt for the overarching 'A intends to convey p'.

xvi The requirement that the speaker believes the literal content to be false (or at least doesn't believe that it is true) shows, I take it, that what is required here is a complete, propositional or truth-evaluable content (i.e. more than Bach's propositional radical or Sperber and Wilson's incomplete logical form). xvii Note that Saul offers a conditional definition of lying which in effect needs to list all possible kinds of speech act involved in (iv) and then claims: if $\mathrm{S}$ believes $\mathrm{p}$ to be false and $\mathrm{S}$ is not engaged in one of these pre-listed acts, then $\mathrm{S}$ is lying. However, given the difficulties of providing such an exhaustive list for (iv), I think defining lying (partly) in terms of the content that $S$ intends to convey ( $p$ vs. $p^{*}$ ) is preferable.

xviii So, is the claim that we can lie only with minimal content - that if the intended content is pragmatically adjusted (beyond disambiguation and reference assignment) then it is simply not possible for the speaker to be lying? Attractive as this claim is, I think it would be too strong. While the pattern of truth-values in (i) is sufficient for lying, it probably isn't necessary (I'm grateful to an anonymous Reviewer, and to Anders Schoubye and Mikkel Gerken for raising this worry). For instance, in the Clinton case (to be examined next in the text above), although the general opinion is that Clinton did not lie, this is not a universal opinion. Or, as a Reviewer suggested, isn't it the case that someone who responds to the question 'Have you eaten yet?' with 'I've had breakfast' would be open to a charge of lying if they hadn't had breakfast today? If right, this would show that although minimal content was relevant to assessments of lying on some occasions, on others explicature content is relevant. There are also other interesting cases; e.g. the use of ambiguous expressions or Sorenson 2017 and Stokke's 2017 discussion of lying via conventional implicatures. Two points however: first, cases involving lying-via-explicature do seem significantly more controversial than ones involving lying-via-minimal-content, thus I'd contend that grasp of minimal content underpins cases which are core to the concept of lying, even if interlocutors then go on to apply the notion of lying in a somewhat broader range of cases (where any such extension is always open to question by others in a way that judgment of minimal-content-lies are not). Second, the possibility that we might sometimes be judged to have lied with pragmatically enriched content doesn't, I think, support the Reviewer's further worry that this position would be tantamount to embracing some kind of contextualism.

xix The concern about completion cases leads Saul 2012: 57 to adopt the following constraint on asserted content:

(NTE) A putative contextual contribution to what is said is a part of what is said only if without this contextually supplied material, S would not have a truth-evaluable semantic content in C.

xx A minimalist might maintain that there is ellipsis here since Clinton's utterance occurred in the context of answering the question as to whether he had "suborned perjury by encouraging a 24 -year-old woman, 
former White House intern, to lie under oath in a civil deposition about her having had an affair with you. Mr. President, is that true?” Given the presence of linguistic material talking about both Clinton and Lewinsky in the preceding dialogue, ellipsis might be expected here (see Borg 2012: Chapter 6 on the compatibility of minimalism and ellipsis, since the latter process does not, unlike free enrichment, conjure semantically relevant content out of the ether, as it were, but provides a formally tractable mechanism for cutting and pasting elements from the explicit linguistic surroundings of a sentence).

xxi Thus even on Saul's own definition, and assuming the minimal content for (4), it seems that Clinton's utterance would not count as an instance of lying, since on this interpretation Clinton would be engaged in (deceptive) loose talk (presumably one of the activities included in the 'etc' part of: 'if a speaker is not using metaphor, hyperbole, irony, etc.').

xxii Note this isn't to claim that it is impossible to lie with a sentence which expresses a trivial falsehood given a situation where a speaker is heard as intending to convey the trivial falsehood this would indeed suffice for a charge of lying. The point is rather that, given the trivial nature of the claim, situations in which that content (rather than an explicature content) is judged as the intended content may be thin on the ground.

xxiii Saul's excellent discussion notes that the objection she raises is not an objection to minimalism per se, since that view was not supposed to be an account of 'what is said' at all, but of a theoretical notion of semantic content. As noted, though, one aim of this paper is to show that minimalists were too quick to cede control of what is said to pragmatically enriched content. Though it is absolutely right that if what is said is understood as dictated by judgements of reported speech (as Borg 2004, 2012, Cappelen and Lepore 2005 seem to assume) then minimal semantic content is fairly redundant, but there are other versions of what is said which do track minimal content. This recognition - that 'what is said' is a composite notion and that some intuitive judgements are sensitive to minimal content - is present in a nascent form in Borg 2012: 14-15.

xxiv Indeed, a potentially promising way of understanding these non-literal speech acts, such as metaphorical speech, irony and sarcasm, is in terms of cancelling a speaker's strict linguistic liability. ${ }_{\mathrm{xxv}}$ There is a debate to be had about exactly what is involved in incurring the lesser charge of misleading rather than lying. It seems clear that the sense in which it is a 'lesser charge' can't be a straightforwardly moral one, for (as Saul 2012 stresses) the upshot of misleading is often as morally blameworthy as the result of lying. Instead then the greater culpability surrounding lying seems to be specifically linguistic - the content one is responsible for simply via the words one produces.

xxvi And note that the minimal content here must be truth-evaluable (rather than a mere propositional radical or incomplete logical form) as the distinctions drawn depend on speakers holding minimal contents true or false. This point is discussed further in $₫ 5$.

xxvii Lovell and Christmas Ltd v Wall (1911) 104 LT 85.

xxviii The move away from literalism arguably reached its height in Investors Compensation Scheme Ltd v West Bromwich Building Society (1998) 1 All ER 98, where Lord Hoffman stated "The background was famously referred to by Lord Wilberforce as the 'matrix of fact', but this phrase is, if anything, an understated description of what the background may include. Subject to the requirement that it should have been reasonably available to the parties...it includes absolutely anything which would have affected the way in which the language of the document would have been understood by a reasonable man". xxix For an excellent related discussion, see Timothy Endicott's paper 'Equity and Interpretation', presented at the $2^{\text {nd }}$ IP/IALS/CUNY workshop on Philosophy of Language and Law, Institute of Philosophy, October 2016. (Thanks are due to Prof. Endicott for making the text of his talk available.) Endicott discusses Aristotle's notion of epieikeia or equity (Nichomachean Ethics, Book V, Ch. 1, 1129a-1129b), which is 'a correction of law where it is defective owing to its generality'. This notion is also discussed in Aquinas and in the legal textbook Doctor and Student (St. German 1531). The idea is that exceptions to laws stated in general terms may be permissible not because apparently general laws in fact contain a tacit exception for non-standard cases (i.e. that the laws should be read as pragmatically enriched) but because judges can and should be able to apply a principle of equity in applying general rules. Again the point is that to so much as understand the Aristotelian position here we need a grasp of the truth-evaluable minimal contents laws may express. Finally, a further rich source of evidence for the role of minimal content (omitted here for reasons of space) comes from biblical literalism (and its role in underpinning legal enactments from the condemnation of Galileo through to the Jim Crow laws in the US).

xxx One reviewer expressed the worry with an earlier version of the paper that all the examples given were cases where the sentences in question plausibly did express a proposition on the basis of words and structure alone (e.g. conjunction cases) rather than what we might term 'incompleteness' cases, where there seems to be no proposition at all to recover prior to pragmatic enrichment (e.g. 'ready', 'enough', 'tall' cases). The inclusion of the 'use a firearm' example is an attempt to provide an actual incompleteness case, as (arguably) it is an example of an expression that contextualists would view as incomplete prior to 
pragmatic adjustment. For compare Recanati's 2004: 91 discussion of 'cut' (drawing on Searle 1992: 180). Recanati notes that the minimalist will claim that a sentence like 'Jack cut the grass' expresses something that has "literal conditions of satisfaction independent of background conditions... something very abstract, involving the constant, underspecified meaning of 'cut"'. Yet he goes on "The contextualist remains sceptical. To get something genuinely evaluable... we need background conditions. We cannot specify a determinate proposition which the sentence can be said literally to express, without building unarticulated assumptions into that proposition". And as for 'cut' so for 'use', we might think.

Although of course, we might also not think - perhaps, it might be objected, the only true instances of incompleteness are words like 'ready' and 'enough' (and the Reviewer is quite right to point out that these terms are rarely if ever used in legislation without further definition in the text, though they are, perhaps, more common amongst children who like to exploit minimal contents, e.g. the child who says "I'm ready" but then seeks to avoid censure when found not to be ready for school by claiming "I just said I was ready for something, I didn't say I was ready for school"). However this potential difference of opinion about what counts as an incompleteness case raises, I think, a worry with the claim of incompleteness itself. For as minimalists have argued, the distinction between sentences which intuitively express complete propositions and sentences which intuitively fail to do so is itself questionable and risks collapsing into the claim that this or that theorist intuitively feels that this or that sentence doesn't express a complete proposition, while other theorists find the sentence in question complete (see the online exchange between Herman Cappelen, Ernie Lepore and Kent Bach which culminates in Bach's 'From the strange to the bizarre', available at: http://userwww.sfsu.edu/kbach/reply2toC\&L.pdf. Also Borg 2012: $82-87$, particularly p.85, footnote 6). That this is a genuine worry here might perhaps be illustrated by the fact that one of the cases discussed in the original version of the paper - Clinton's utterance of (4) 'There is no improper relation' - is, it seems, taken by at least one theorist - Saul - to be a case which requires completion prior to recovery of a truth-evaluable content. As she writes 2012: 42 "notice that [4] is in need of Completion: until it is supplemented in some way, no particular improper relation is specified.

According to Bach, then, [4] says nothing truth-evaluable”.

xxi Hansen 2008 also argues for the need for minimal content to explain both perjury judgements and to account for linguistic practices in cross-examination. Though note that, as discussed in Sorenson 2017, the case of People vs. Meza, 1987, 188 Cal. App. 3d 1631, where a potential juror was convicted of perjury for remaining silent after a judge asked whether anyone present knew the defendant, shows the need to allow for enthymematic content.

xxxii In fact the Laws of cricket themselves explicitly recognise this distinction, with Law 1.4 stating: "The captains are responsible at all times for ensuring that play is conducted within the spirit and traditions of the game as well as within the Laws". Thanks to Henry Trotter for discussion.

xxxiii It might be worth contrasting the developmental delay in recovery of pragmatically enhanced content with the early on-set capacity to exploit minimal meaning. So, for instance, it has been shown that children from a very young age (25-28 months) are capable of lying to conceal their own transgressions, with lying behaviour apparently reaching something of a peak around 43-48 months (see Evans et al 2013, also Wilson et al 2003). Thus, in a 'peek test' for children in the $43-48$ month bracket, $62.5 \%$ of children peeked at a hidden toy after being instructed not to, of whom $90 \%$ then lied to conceal this fact.

xxxiv Some studies also suggest that the developmental patterns associated with metaphor mirror those seen here for scalar and conjunction enrichments; see Noveck et al 2001, Winer et al 2001.

xxxv I should note that in their Experiment 1, probing judgments of speaker commitment, Sternau et al found no difference in responses between bare linguistic meaning and explicature content. However, there is some reason to think this may have been an experimental artefact. First, their Experiment 2, which probed subjects' views on the extent to which a speaker could deny a given content, yielded a different result (which held apart bare linguistic meaning and explicature content). Second, it may be that the lack of differentiation between the two categories of meaning in Experiment 1 was a result of the examples of explicature contents chosen, where six out of the twelve prompts involved contents which, on at least some views, would count as minimal contents rather than true explicatures. Thus 6 prompts involved reference assignment and 6 involved 'grammatical completion' (e.g. 'on the left' being interpreted as 'the salt is on the left'), both of which some minimalists (e.g. Borg 2012) would take as content delivered by linguistic understanding rather than semantically intrusive pragmatic reasoning. The other twelve prompts were more standard examples of explicature content (10 cases of default enrichment, such as 'it's raining' to 'it's raining here', and two cases of conjunction strengthening). Thanks to Marit Sternau (pc) for providing further details here.

xxxvi Note that because conversational liability is held to be a matter of degree, there may be no sharp cutoff point between explicature and implicature (something Relevance Theorists have always been keen to stress), so there may be differences of opinion about whether a given pragmatically enhanced content has in fact been asserted or implicated. 
xxxvii Goldberg 2015 also argues for the context-sensitivity of assertion, though his argument is that the particular epistemic norm governing assertion should be allowed to shift across contexts (so that sometimes one should assert $\mathrm{p}$ only if one knows $\mathrm{p}$, sometimes only if one has a justified belief that $\mathrm{p}$, etc.). Combining the two views we would say that a context of utterance will play a role in fixing (i) the content a speaker asserts (minimal versus explicature content) and (ii) the degree of epistemic responsibility the speaker is expected to have for that content. 